\title{
A EDUCAÇÃO ESCOLAR DO INDÍGENA BRASILEIRO
}

\section{THE SCHOOL EDUCATION OF THE BRAZILIAN \\ INDIGENOUS}

\begin{abstract}
Claudinei de Aro Poço
Mestre em Educação pela Universidade Nove de Julho. São Paulo - SP- Brasil

claudinei.aro@bol.com.br
\end{abstract}

Elaine Teresinha Dal Mas Dias

Doutora em Psicologia Escolar e do Desenvolvimento Humano pela Universidade de São Paulo (USP). Professora do curso de Psicologia e do Programa de Pós-Graduação em Educação da Universidade Nove de Julho. São Paulo - SP - Brasil

etdmdias@terra.com.br

Resumo: O presente artigo tem por objetivo apresentar os impasses que ainda existem quanto à formação de escolas específicas para os povos indígenas do Brasil. A Constituição de 1988, a LDB de 1996 e, por último, a promulgação da Lei no 11.645 garante a preservação de conhecimentos dessas populações no sentido de preservar seus costumes e reconhecê-las como grupos étnicos. Entretanto, na contemporaneidade, a imagem do indígena continua a ser ilustrada nos livros didáticos de História do Brasil de escolas regulares, privadas e públicas, de maneira distorcida e estereotipada, o que contribui para a manutenção da discriminação, do preconceito e da invisibilidade. Essas comunidades lutam por espaço na sociedade brasileira e pedem que sejam respeitadas suas formas de ensino e características étnicas.

Palavras-chave: Educação escolar indígena. Discriminação. Invisibilidade.

Cadernos de Pós-graduação, São Paulo, v. 17, n. 1, p. 33-53, jan./jun. 2018. 
Abstract: The current paper aims to present still existing impasses regarding to the formation of specific schools for the indigenous peoples of Brazil. The Constitution of 1988, the LDB of 1996 and, finally, the promulgation of Law $n^{\circ} .11 .645$ guarantees the preservation of knowledge of these populations with reference to the maintaining their customs and recognizing them as ethnic groups. However, in contemporary times, the image of the indigenous continues to be illustrated in the textbooks of History of Brazil of regular, private and public schools, in a distorted and stereotyped way, which contributes to the maintenance of discrimination, prejudice and invisibility. These populations struggle for space in Brazilian society and demand that their teaching methods and ethnic characteristics be respected.

Keywords: Indigenous school education. Discrimination. Invisibility.

\section{INTRODUÇÃO}

educação escolar indígena segundo Cohn (2016) é discutida atual-
mente a partir de dois pontos de vista: o da política do Estado, regulamentado pela Constituição de 1988, e o da política indígena, por meio do qual cada aldeia ou comunidade no Brasil pleiteia a implantação de escolas para as suas respectivas populações, bem como o prosseguimento dos seus estudos, contemplando desde a educação infantil até o nível superior. Entretanto, a fundação e a formulação de instituições de ensino em terras indígenas têm impactos econômicos e políticos, demandando a criação de postos de trabalho e a intervenção de lideranças indígenas - estas configuradas por caciques e pajés, que estão à frente de seus povos com o intuito de debater os seus direitos e também sua cultura.

A autora ainda afirma que a implementação de escolas nas aldeias requer discussões a respeito de qual modelo escolar essas comunidades almejam. Contudo, a inauguração de escolas em terras indígenas leva à necessidade de pesquisar se o objetivo 
desses povos é gerar, produzir ou fazer circular conhecimentos. Desse modo, na realização de conferências e mesas-redondas que debatam as políticas culturais é preciso pleitear também a discussão sobre a escolarização do indígena brasileiro na contemporaneidade.

Todavia, as demandas da educação escolar indígena não são de natureza homogênea, uma vez que cada comunidade apresenta inquietações e problematizações que diferem das encontradas nas demais. Sendo assim, discorrer sobre a educação escolar indígena no Brasil, por meio de uma abordagem etnográfica, requer destacar as lutas em direção a uma escola específica e diferenciada, que partem de ações atreladas às políticas integracionistas e não à política de Estado, que tende a falar da escolarização do indígena de maneira uniforme.

Hoje, as crianças e jovens indígenas passam grande parte de seu dia no ambiente escolar e algumas têm a finalidade de sequenciar seus estudos para serem futuros educadores interculturais. Além disso, objetivam construir as suas próprias escolas, retratando nelas, referências que dizem respeito aos conhecimentos que circulam nas aldeias indígenas brasileiras nos dias atuais, pois muitos deles costumam ser oriundos dos ensinamentos que se adquirem no dia a dia, fazendo parte da educação indígena e favorecendo com que muitos alunos busquem também o interesse para o aprofundamento na formação xamânica, esta geralmente conduzida pelos mais velhos da comunidade. Desse modo, a autora propõe que:

[...] a etnografia é o melhor instrumento que temos para enfrentar, analiticamente, este desafio: entender a(s) demanda(s) indígena(s) por escola, de um lado, as possibilidades de escolarização que se lhes apresenta, de outro, e os impactos que isto tem nos regimes de conhecimentos ameríndios. (COHN, 2016, p. 315) 
Ao mesmo tempo em que a legislação garante no artigo 32 da Lei de Diretrizes e Bases n 9.394/96 (LDB) que o ensino fundamental será ministrado em língua portuguesa para as comunidades indígenas, as populações têm garantido o uso de suas línguas maternas e a manutenção de seus processos próprios de aprendizagem.

Há um contrassenso a respeito da LDB voltada para os povos indígenas e de seu cumprimento, pois sua promulgação não certifica que haverá educadores indígenas nas escolas regulares que desenvolvam currículos de acordo com as realidades desses povos. De certa maneira, isso retrata que a legislação insere essa minoria no sistema de diretrizes e bases da educação nacional, mas não oferece, por exemplo, capacitação aos educadores não- indígenas o acesso quanto aos seus costumes e modos de vida.

Os artigos de $n^{\circ} 78$ e 79 da LDB decretam que o sistema de ensino da União, em conjunto com o apoio das agências federais, tem por objetivo dar apoio à cultura das populações indígenas e assistência a elas, promovendo por sua vez, programas integrados de incentivo à pesquisa e à educação escolar bilíngue e intercultural. Esses programas devem rememorar suas trajetórias históricas, reafirmando-as como pertencentes aos povos originários, conduzindo desse modo, à valorização de suas línguas e seus costumes, assim como garantir-lhes o acesso a informações e conhecimentos das sociedades não indígenas que compõem a nacionalidade brasileira. Entretanto, o exercício disso só pode ocorrer com a participação assídua das comunidades indígenas nos planejamentos em prol da escolarização, pois o principal objetivo nesse contexto é a formulação de currículos específicos que incluam práticas culturais em consonância com cada etnia (GRUPIONI, 2001b).

Anteriormente à Constituição de 1988, Grupioni (2001b) discorre que a relação do Estado com os povos indígenas era fundamentada numa política integracionista de caráter individualista, uma vez que pretendia incorporar o cidadão indígena à sociedade nacional. Todavia, com a nova Constituição a relação entre Estado com as populações 
indígenas passou a serem reconhecidas como sociedades étnicas constituídas por agrupamentos com direitos e deveres, em uma perspectiva de respeito às diferenças, diferente da política de intolerância diante da diversidade cultural dessas sociedades que predominaram durante cinco séculos.

Para Silva (2001), os debates que circundam a educação escolar do indígena brasileiro promovem descortinar as realidades que se configuram nas aldeias, pois uma das reivindicações do indígena na contemporaneidade em termos de escolarização é o acesso à aprendizagem com o manuseio das tecnologias, adquirindo conhecimento e domínio dessas ferramentas, conforme conferência apresentada no Seminário Internacional - Ciências, Cientistas e a Tolerância, realizado entre 18 a 21 de novembro de 1997, na Universidade de São Paulo - USP.

Hoje, a criação de escolas indígenas diferenciadas, além de ter “[...] um papel importante na construção de diálogos interculturais e projetos políticos e de autogestão econômica, tecnológica, cultural e linguística por grupos indígenas específicos”, faz parte dos “[...] preceitos igualmente estabelecidos na legislação e nas políticas públicas educacionais brasileiras.” (SILVA, 2001, p. 101).

Silva (2001) assevera que o conceito de educação oferecida aos povos indígenas no Brasil avançou de uma escola rural, missionária e catequética para uma educação escolar específica autônoma que aborda no plano pedagógico modos próprios de aprendizagem de acordo com as particularidades de cada comunidade, percorrendo também na área jurídica o reconhecimento à diferença sociocultural e ao campo político. Isso ocorreu em razão de associações locais e regionais que têm por função prestar assessoria aos educadores indígenas, havendo espaço para discussões da situação escolar de cada comunidade.

Os Núcleos de Educação Indígena (NEIs), instituídos por meio da Portaria Interministerial de $\mathrm{n}^{\circ}$ 559, de 26 de abril de 1991, em nível estadual objetivam ter a 
participação de representantes legais dos povos indígenas locais em ações no âmbito da educação escolar indígena; no nível municipal, são incumbidos da remuneração do trabalho de docentes indígenas e não indígenas que atuam em escolas locais. Apesar da institucionalização desses núcleos pelo país e da legislação, Silva (2001) pontua que até este ano há ainda rupturas entre a consolidação plena da lei e das práticas políticas estabelecidas e administradas no país.

\section{A LEI No $11.645 / 08$}

A Lei no 11.645/08 incluiu a obrigatoriedade nos ensinos fundamental e médio da temática História e Cultura Afro-Brasileira e Indígena, a qual tem por objetivo retratar a historicidade e a luta dos negros e dos povos indígenas no Brasil, apresentando também suas culturas na formação da sociedade nacional (BRASIL, 2008).

A inclusão dessa lei nas escolas regulares é o resultado de ações da luta dos negros e dos povos originários no Brasil, em conjunto com entidades como organizações não governamentais (ONGs), universidades e igrejas, que contribuíram para o reconhecimento dessas sociedades étnicas (MEDEIROS, 2012).

Em âmbito internacional, Medeiros (2012) descreve que o marco se firmou por meio da Convenção no 169 da Organização Internacional do Trabalho sobre Povos Indígenas e Tribais de 1989 (OIT), estabelecendo para os Estados signatários que, diante das relações instauradas com as populações indígenas, sejam respeitados seus costumes, suas tradições e suas referências culturais.

Essa convenção se aplicou a todos os países em que os habitantes são descendentes da mesma região geográfica que era ocupada pelos povos originários e pelos que viveram durante o período da colonização (BRASIL, 2011). 
No que diz respeito à educação escolar do indígena brasileiro, a Convenção afirma, especificamente no artigo 31, que:

\begin{abstract}
Medidas de caráter educacional deverão ser tomadas entre todos os setores da comunidade nacional, particularmente entre os que se mantêm em contato mais direto com os povos interessados, com o objetivo de eliminar preconceitos que possam ter em relação a esses povos. Para esse fim, esforços deverão ser envidados para garantir que livros de história e outros materiais didáticos apresentem relatos equitativos, precisos e informativos das sociedades e culturas desses povos. (OIT, 2011, p. 37)
\end{abstract}

Essa medida visa desconstruir o estereótipo que persiste no século XXI do indígena brasileiro, retratado nos livros didáticos de História do Brasil geralmente com corpos nus, pintados e adornados com colares, cocares, arcos, flechas, vivendo dentro de uma oca e distantes dos centros urbanos (BONIN, 2012). Além disso, “[...] Há outras noções que são ainda mais preconceituosas: por um lado, os índios são selvagens, primitivos, preguiçosos, canibais, poligâmicos; por outro, são ingênuos, inocentes, bondosos e protetores do meio ambiente." (MEDEIROS, 2012, p. 55).

Os estereótipos criados pelos não indígenas segundo Bonin (2012) são descontextualizados, em razão de desconsiderarem a riqueza cultural que esses nativos carregam, ocasionando a muitas comunidades o estranhamento de como são vistos por outras referências culturais. Subentende-se, em razão disso, a necessidade de eliminar o tabu que foi formado sobre os povos indígenas pelos brancos, de que vivem todos aldeados e longe da população urbana.

A origem desses clichês está na historiografia fundamentada no período colonial e registrada na história nacional pelo Instituto Histórico e Geográfico Brasileiro (IHGB), que criou a imagem do indígena como um herói nacional e o habitante mais fidedigno das terras ocupadas em solo brasileiro. Contudo, Bonin (2012) informa que se formou à época uma classificação dos povos indígenas em bons e maus, cuja distinção dava-se pelo processo das populações que estabeleciam ou não diálogos com os 
brancos. As comunidades que não tinham contato com outras culturas eram consideradas boas, e as que estabeleciam vínculos com outras organizações sociais pressupunham-se como más, havendo interdição da interculturalidade.

Retomando a temática indígena nas escolas regulares, os avanços desta abordagem necessitam de aprofundamentos no que tange às particularidades e aos costumes desses povos, embora os livros e currículos escolares apresentem hoje algumas transformações quanto à historicidade, no sentido de romper com o velho paradigma estabelecido sobre o indígena brasileiro (BONIN, 2012). Para que essa ação seja realizada no processo de ensino e aprendizagem nos ensinos fundamental e médio, é preciso subverter as representações redutoras sobre o imaginário do homem,

[...] disseminando informação sobre a constituição histórica das sociedades indígenas (diferenças culturais); difundindo informação atualizada sobre as sociedades indígenas que habitam o território brasileiro, sobretudo o conhecimento produzido pelos próprios autores/pesquisadores indígenas em nível local; auxiliando o aluno na construção de conceitos de identidade, alteridade, cultura, tolerância, diversidade; problematizando situações cotidianas e organizando estratégias de aprendizagem compatíveis a idade da criança e a complexidade dos conteúdos; promovendo a mudança de atitudes antiéticas, tais como o estigma, preconceito, estereótipo, discriminação e racismo. (FREITAS, 2010, p. 169)

Com o propósito de os currículos escolares virem ao encontro das populações indígenas é necessário que se promova espaços no âmbito educacional escolar para ouvir esses sujeitos e verificar quais são os pormenores na construção de escolas específicas, pois muitas vezes as discussões no que tange à escolarização do indígena se restringem ao olhar dos brancos, o que dificulta de conhecer que escola essas populações almejam.

A Lei n ${ }^{\circ}$ 11.645/08 foi promulgada porque se tornou “[...] necessário identificar problemas no modo como os povos indígenas eram tratados no ensino de história até recentemente, os avanços já conquistados e os limites que ainda nos colocam desafios." 
(MEDEIROS, 2012, p. 51). A História do Brasil foi sempre ensinada nas escolas regulares como uma ideia homogênea, não se atentando ao fato de a população brasileira compor diversas organizações sociais (BITTENCOURT, 2009). Entretanto, esse quadro começou a ser modificado em 1990, ano em que novas investigações realizadas por historiadores acerca dos nativos surgiram. Passaram a ser estudadas as relações que eram feitas entre eles e os colonizadores, com o objetivo de mostrar que, mesmo diante dos conflitos, estreitavam-se alianças, ocorrendo segundo Almeida (2010), processos de trocas e negociações.

Nesse sentido, Medeiros (2012) afirma que:

[...] Se é inegável que os diferentes povos originários cumpriram papel importante na história nacional, os reflexos desse movimento no ensino de história, no entanto, ainda são tímidos. Eles começam a aparecer nas páginas dos livros didáticos, mas ainda de forma coadjuvante, normalmente destacados do restante do texto, em um box de informações adicionais. (MEDEIROS, 2012, p. 52)

Essa fala mostra que os indígenas estão marcados pela invisibilidade, pois a história é produzida e ensinada com base na colonização, a contar de 1500, ignorando todo o passado anterior ao século XVI. Isso certifica que as referências culturais são oriundas da Europa e dos colonizadores, que desconstruíram a diversidade étnica que há no Brasil, pois, ainda permanece nos livros didáticos das escolas regulares a imagem dos nativos subvertida pelos olhares dos colonizadores. Contudo, desde 1980, pesquisas históricas referentes às sociedades primitivas foram realizadas por arqueólogos e antropólogos com o intuito de descobrir as riquezas e vestígios deixados pelos povos originários, objetivando-se retirar o conceito de "[...] "pré-história" - entendido como período que antecedeu a escrita - e [adotando] a expressão “pré-colonial”, esclarecendo que seu objeto de estudo são as sociedades indígenas que aqui viviam antes da colonização portuguesa.” (MEDEIROS, 2012, p. 52). 
Em termos de historiografia, Monteiro (1994) informa que estudos antropológicos corroboraram olhar para os indígenas como organizações sociais formadas por agrupamentos com costumes e práticas culturais distintas das do branco. Dessa maneira,

[...] Nos livros didáticos, já se encontram partes exclusivamente dedicadas às populações ameríndias que habitavam o continente antes da chegada dos europeus. Trata-se do povoamento da América. O uso da palavra "descobrimento" para referir-se a esse momento tem sido relativizado, sendo até mesmo trocado por outros, como achamento, conquista, invasão, encontro. (MEDEIROS, 2012, p. 52)

O processo de silenciar os povos indígenas se associa também ao etnocídio que se perpetuou ao longo dos últimos quinhentos anos, e, até meados do século XX. Segundo Medeiros (2012), acreditava-se que os indígenas estavam em extinção em função de serem aculturados.

Para Medeiros (2012), o debate na contemporaneidade acerca dessas populações refere-se ao estereótipo que ainda há sobre os indígenas nos livros didáticos, reforçando muitas vezes que indígenas são somente aqueles que vivem alocados na Região Norte do Brasil, especificamente no estado de Amazonas, ou no Centro-Oeste como, por exemplo, o Xingu.

Outro fator comprometedor é a indiferença com o indígena por parte da historiografia nacional. De acordo com Medeiros (2012, p. 54):

[...] Quando o Brasil deixa de ser colônia, os índios deixam de existir - ou assim se parece, pois eles desaparecem da narrativa histórica. Existe um lapso de tempo que nem sequer a historiografia conhece para contar. A falta de estudos sobre os indígenas nos séculos XIX e XX reflete-se na escola, períodos em que, de fato, eles não aparecem por lá. Essa invisibilidade na história do Brasil Imperial e Republicano também contribui para uma visão fossilizada dos índios, pretéritos ou extintos. 
Atualmente, os povos indígenas são relembrados no âmbito educacional escolar apenas no dia 19 de abril, em que se comemora o Dia do Indígena. Entretanto, rememorá-los somente nessa data dá a entender que “[...] O discurso comemorativo opera generalizações, simplificações, caricaturas, trazendo um conjunto fixo de informações, muitas vezes descontextualizadas e pouco significativas.” (MEDEIROS, 2012, p. 54). O que ocorre nas escolas regulares parece agravar a discriminação e o preconceito com os nativos, distorcendo a sua verdadeira imagem, pois a maneira como são representados leva a crer que permanecem os mesmos povos originários do século XVI, isolados da sociedade nacional, sendo retratados pela visão europeia à época do suposto descobrimento.

\section{EDUCAÇÃO ESCOLAR INDÍGENA}

A primeira Conferência Nacional de Educação Escolar Indígena (CONEEI), realizada em novembro de 2009, na cidade de Luziânia - estado de Goiás - em parceria com a Fundação Nacional do Índio (FUNAI) e o Conselho Nacional de Secretários de Educação (CONSED), promoveu um encontro entre pais, estudantes, educadores e representantes das comunidades indígenas. O propósito da conferência era discutir a educação escolar em conjunto com populações que já se encontram em terras oficializadas e reconhecidas pelo Governo Federal, com a proposta de criar escolas nas aldeias conforme o estabelecido pelo Decreto $\mathrm{n}^{\circ}$ 6.861, de 27 de maio de 2009, em seu artigo primeiro: "a educação escolar indígena deverá ser organizada com a participação dos povos indígenas, observada a sua territorialidade e respeitando suas necessidades e especificidades." (BRASIL, 2009).

A conferência percorreu a princípio 28 terras indígenas do estado de Mato Grosso do Sul e oito do estado do Amazonas, totalizando 36 povos, com o intuito de 
estabelecer políticas educacionais em consonância com a diversidade cultural. A proposta também assevera a essas populações o emprego de suas línguas maternas e discorre sobre o desenvolvimento de currículos específicos, partindo da ideia de construir materiais didáticos que referenciam a cultura e os costumes respectivos de cada comunidade (BRASIL, 2009).

Cabe destacar que o Referencial Curricular Nacional para Escolas Indígenas (RCNEI), elaborado em 1998 pelo Ministério da Educação (MEC), foi utilizado pelas populações indígenas como parâmetro na construção de projetos pedagógicos em diversas regiões do Brasil. No entanto, alguns professores indígenas pleitearam o cumprimento de novos projetos educacionais que empregasse o uso de línguas maternas; o qual já fora promulgado na Constituição de 1988 por meio do artigo 210, decretando que:

Serão fixados conteúdos mínimos para o ensino fundamental, de maneira a assegurar formação básica comum e respeito aos valores culturais e artísticos, nacionais e regionais. Parágrafo Segundo: O ensino fundamental regular será ministrado em língua portuguesa, assegurada às comunidades indígenas também a utilização de suas línguas maternas e processos próprios de aprendizagem. (BRASIL, 1998, p. 122).

Como cada população apresenta proposições distintas sobre a educação escolar, torna-se mais difícil chegar em uma solucão que possa atender suas necessidades. Apesar de a oralidade ser considerada como instrumento pedagógico em grande parte das comunidades indígenas do Brasil, o processo de ensino e aprendizagem possui peculiaridades e nuanças que variam entre os aldeamentos, geralmente estando em conformidade com as tradições, os costumes, os hábitos e as práticas próprias que são fundamentadas na própria comunidade. Diante disso, o RCNEI objetiva servir de base para que cada escola indígena construa o seu próprio referencial em direção às suas singularidades, tendo função formativa e não normativa no que concerne à escolarização dos povos indígenas (BRASIL, 1998). 
Além disso, para que a educação escolar do indígena brasileiro seja fundamentada na preservação da cultura é necessário pensar a formação de educadores indígenas. Nesse sentido, Paladino e Almeida (2012, p. 38-39) afirmam que somente,

Nos anos 1980, criou-se um movimento de professores indígenas nos estados de Amazonas, Roraima e Acre, que se reuniram numa organização e realizaram, a partir de 1988, reuniões anuais para analisar e discutir questões relacionadas à atividade educacional que desempenhavam, e trocar experiências e conhecimentos sobre as ações que cada povo executava para conseguir uma escola adequada às suas necessidades.

As organizações de educadores indígenas ocorreram por meio de mobilizações das comunidades, que passaram a discutir esta questão com o pressuposto de a FUNAI, em conjunto com os governos municipais e estaduais, garantir a escolarização indígena, contratando professores indígenas e fornecendo materiais didáticos exclusivos a essas comunidades, objetivando-se também um ensino bilíngue (PALADINO; ALMEIDA, 2012).

Atualmente, a criação de uma educação escolar indígena específica e diferenciada busca a integração dos indígenas na sociedade nacional com a finalidade de dar visibilidade a essas comunidades, além de discutir seus modos de vida e práticas próprias de aprendizagem, as quais objetivam também a valorização de seus costumes e hábitos (PALADINO; ALMEIDA, 2012).

A despeito da legislação internacional, como a Convenção 169, Bergamaschi e Silva (2007) pontuam que os progressos no que tange à escolarização indígena são paulatinos e que poucas ações foram realizadas para mudar a realidade das escolas, e afirmam que:

Entre a consolidação de uma nova perspectiva para as políticas públicas em educação e a concretização de processos de "indianização" da instituição escolar - ou seja - de colocar a escola a serviço dos interesses e necessidades dos povos indígenas, enquanto partes de seus projetos de presente e futuro, o que têm feito a diferença positiva são as iniciativas pensadas, coordenadas e avaliadas pelos próprios índios, através de seus diferentes

Cadernos de Pós-graduação, São Paulo, v. 17, n. 1, p. 33-53, jan./jun. 2018. 
movimentos, em especial o de professores indígenas. (BERGAMASCHI; SILVA, 2007, p. 129)

Além da demarcação de terras, a criação de escolas específicas representa para essas comunidades autonomia na sociedade em que foram inseridos. Desse modo, os argumentos que favorecem a inauguração de escolas indígenas frequentemente são baseados na cultura; esta, quando é valorizada pela sociedade nacional, viabiliza aos povos indígenas ter liberdade para expor a escola que desejam (GRUPIONI, 2001). Enquanto não for reconhecida a diversidade cultural que há no Brasil, dificilmente se logrará êxito na luta dos indígenas por uma escola que rememore seus preceitos e as convicções acerca de suas histórias.

Os princípios que estão contidos na legislação nacional e internacional convergem para novas escolas que, em princípio, atendam as demandas dos agrupamentos indígenas. Todavia, isso não é suficiente se não forem abertos espaços nas secretarias municipais e estaduais de educação em conjunto com as famílias de sua comunidade concomitante aos educadores indígenas para questionar quais escolas querem para as suas respectivas populações. Desse modo,

[...] a participação ativa dos professores indígenas e de suas comunidades em todos os processos de construção e definição da escola e de seu projeto pedagógico é condição primeira para que se consiga edificar uma escola de qualidade, que respeite e valorize as especificidades culturais das mais de duzentas sociedades indígenas que vivem no Brasil de hoje. (GRUPIONI, 2001a, p. 96)

As dificuldades em haver uma escola que atenda os povos indígenas se associam também à descentralização da gestão pública, pois no governo Fernando Henrique Cardoso as questões que abrangem a escolarização do indígena brasileiro foram passadas 
inicialmente da FUNAI para o MEC, tendo sido posteriormente incumbidas às secretarias estaduais de educação a coordenação e a supervisão de reivindicações dos povos indígenas por uma escola diferenciada da dos brancos (GOMES, 2012).

Para Gomes (2012) as discussões quanto à educação escolar indígena brasileira é um dos efeitos da política indigenista imperial, com caráter predominante das classes hegemônicas sobre essas populações. Todavia, os discursos de seus tutores legais atualmente, vislumbram,

[...] Fortalecê-los significa ensinar as matérias formais da educação tradicional brasileira, primeiro através de suas línguas maternas e usando de exemplos de suas culturas e histórias; segundo, incutindo-lhes um sentindo de autoestima e valorização de suas culturas. A educação vira, assim, duplamente um instrumento de proteção cultural e de conhecimento do mundo externo. (GOMES, 2012, p. 117)

Um dos objetivos da escolarização envereda para a formação de professores que possam ensinar os jovens no entendimento e funcionamento de outras culturas, como por exemplo, apresentando-lhes o uso das tecnologias atuais que comumente são usadas pelos não indígenas. No que diz respeito à área econômica, Gomes (2012) discorre que o propósito é inserir essas comunidades na sociedade nacional para que as crianças e os jovens indígenas possam acompanhar o mundo que os rodeia além da aldeia.

Silva (2001) afirma que nas pesquisas antropológicas realizadas entre os anos de 1996 e 1997, a criação de escolas indígenas tinha como objetivo formar e servir de espaço privilegiado às populações indígenas para retratar sobre suas problemáticas, seus saberes e costumes. Além disso, elucidar aos alunos indígenas as políticas públicas e ações afirmativas que foram elaboradas com a finalidade de combater a discriminação e reduzir a desigualdade é fator indispensável para que entendam também seus direitos e deveres na sociedade nacional. 
A educação escolar indígena para alguns líderes e professores indígenas deve incorporar os conhecimentos que são apreendidos pelas crianças e jovens no cotidiano, os quais compõem a educação indígena. $\mathrm{Na}$ visão dessas comunidades, a aprendizagem que se adquire na escola da vida não pode ficar à parte da escolarização. Dessa maneira, as pesquisas realizadas no campo da antropologia, nos últimos tempos, referentes à educação escolar do indígena brasileiro mostram que os diálogos estabelecidos nas escolas indígenas percorrem caminhos comumente atrelados à vida cotidiana e à experiência social que são constituídos em cada aldeia.

A formação dessas escolas hoje serve também como locais de debate para os alunos indígenas quanto às informações que foram construídas pelo branco ao longo da história sobre os povos originários, apresentando conflitos entre saberes e a própria cultura desde a época em que o Brasil foi colonizado pelos portugueses (SILVA, 2001). Sendo assim, as escolas indígenas têm como princípio e fundamento a ideia de que os professores indígenas sejam também futuros pesquisadores de sua sociedade, uma vez que:

[...] esse conhecimento, produzido e acumulado fora das aldeias e dos universos indígenas, poderá tornar-se "objeto de exame, leitura, discussão e crítica, posicionamentos, revisões... Os livros didáticos comercializados, usualmente empregados nas escolas urbanas não indígenas, podem integrar o material a ser examinado criticamente." (SILVA, 2001, p. 115)

As pesquisas realizadas pelos educadores indígenas podem ser a posteriori objetos de estudo para os brancos, desconstruindo ações discriminatórias e preconceituosas que são marcadas ainda hoje, também, pela violência simbólica. Nesse sentido, abarcar estudos dos povos originários em escolas não indígenas implica discutir especialmente questões do campo da História do Brasil com alunos brancos, pois os livros didáticos que foram produzidos nos últimos quinze anos sobre educação escolar indígena demonstram escassez de produção científica de etnólogos, agravando, segundo Silva 
(2001), a discriminação de minorias étnicas pela ausência de informação no que concerne a essas populações nos últimos quinze anos de 1986 a 2001.

Cabe destacar que a forma como a história dos povos indígenas é abordada no ensino da História do Brasil nas escolas dos não indígenas necessita de investigações nos ensinos fundamental e médio; mesmo com os Parâmetros Curriculares Nacionais (PCNs), que retratam em uma de suas temáticas transversais a diversidade e a pluralidade cultural, e com a Lei $n^{\circ} 11.645 / 2008$, subentende-se que as minorias no Brasil são apenas toleradas, prevalecendo nas escolas regulares dos brancos a persistência de um discurso hegemônico,

[...] tantas vezes autoritário, fruto do desconhecimento ou da desconsideração da multiplicidade e da riqueza de saberes e verdades que a diversidade contém e produz. A educação é um campo em que essas certezas parecem poder, lamentavelmente, manifestar-se com uma certa liberdade. (SILVA, 2001, p. 119)

Para que diversidade cultural seja discutida na sociedade brasileira pela via da educação, a formação continuada de docentes das redes públicas e privadas, bem como os cursos superiores de licenciatura, devem promover atividades voltadas para a alteridade, com a finalidade de promover também aos educandos, conhecimentos sobre os grupos étnicos e os povos indígenas do Brasil (SILVA, 2001).

\section{CONSIDERAÇÕES FINAIS}

A educação escolar do indígena brasileiro ainda é pauta de muitas discussões no Brasil, em razão de constatarem que as escolas regulares, sejam elas públicas ou privadas, não empregarem em seus projetos político-pedagógicos (PPP) o que diz a Lei $n^{\circ} 11.645 / 2008$. As temáticas referentes às questões indígenas são abordadas no mo- 
mento presente de maneira insuficiente e, quando aplicadas em sala de aula, são trabalhadas de maneira equivocada, distorcendo a imagem e a representação do indígena brasileiro.

Outro fator que se relaciona à escolarização dos povos indígenas no Brasil é a formação de docentes; revela-se a falta de preparo de educadores não indígenas quanto ao ensino de História nas escolas regulares, pois, quando se deparam com alunos indígenas, em razão de não conhecerem suas culturas e maneiras próprias de aprendizagem, acabam priorizando o ensino para os brancos. Dessa forma, não ocorre o exercício nem o cumprimento da lei em vigor, tampouco a descentralização de uma gestão pública que abranja as particularidades de cada comunidade.

Apesar de a maioria dessas comunidades apresentarem primeiramente como instrumento pedagógico a oralidade, as práticas diferem entre si, em função de seus costumes, hábitos e tradições; isso se configura num dilema aos pesquisadores e estudiosos de educação escolar indígena e também aos gestores e órgãos públicos responsáveis por esses sujeitos, uma vez que, as discussões que são levantadas, como por exemplo, a criação de escolas específicas, resulta muitas vezes na criação de currículos padronizados para esses povos, o que não é adequado em virtude de não haver uma padronização no que abarque as necessidades de todas as etnias.

A discriminação, o preconceito e a invisibilidade que ocorre com os povos indígenas decorrem do não reconhecimento da diversidade cultural que existe no Brasil; os livros didáticos que são distribuídos nas escolas regulares públicas e privadas para os ensinos fundamental e médio tratam os nativos de maneira estereotipada, reproduzindo no processo de ensino e aprendizagem o indígena do século XVI. Isso indica que nas escolas regulares dos não indígenas predominam hoje as referências culturais europeias, com a dominação dos colonizadores sobre os colonizados que não se restringe apenas aos indígenas, mas incluindo também os negros e quilombolas, grupos que passaram 
por processos de violência concreta e simbólica e, que, na contemporaneidade, lutam e reivindicam por espaço na sociedade, empregando seus valores, culturas e costumes.

\section{REFERÊNCIAS}

ALMEIDA, Maria Regina Celestino de. Os indios na história do Brasil. Rio de Janeiro: FGV, 2010.

BERGAMASCHI, Maria Aparecida; SILVA, Rosa Helena Dias da. Educação escolar indígena no Brasil: da escola para índios às escolas indígenas. Agora, Santa Cruz do Sul, v. 13, n. 1, p. 124-150, jan./jun. 2007.

Disponível em: < https://online.unisc.br/seer/index.php/agora/article/view/113>. Acesso em: 17 jan. 2018.

BITTENCOURT, Circe Maria Fernandes. Identidade nacional e ensino de história do Brasil. In: KARNAL, Leandro. (Org.). História na sala de aula: conceitos, práticas e propostas. São Paulo: Contexto, 2009.

BONIN, Iara Tatiana. Educação escolar indígena e docência: princípios e normas na legislação em vigor. In: BERGAMASCHI, Maria Aparecida; ZEN, Maria Isabel Habckost Dalla; XAVIER, Maria Luisa Merino de Freitas (Org.). Povos indígenas e educaşão. 2. ed. Porto Alegre: Mediação, 2012.

BRASIL. Documento-sintese dos documentos finais das conferências regionais de Educação Escolar Indigena. Brasília, DF: MEC/SECAD, 2009.

$<$ http://www.ipea.gov.br/participacao/images/pdfs/conferencias/Educacao_Escolar_Indigena/caderno_propostas_1_conferencia_educacao_escolar_indigena.pdf $>$. Acesso em: 19 jan. 2018.

Decreto n ${ }^{\circ}$ 6.861, de 27 de maio de 2009. Dispõe sobre a Educação Escolar Indígena, define sua organização em territórios etnoeducacionais, e dá outras providências. Diário Oficial da União, Brasilia, 2009.

Disponível em: <http://www.planalto.gov.br/ccivil_03/_ato2007-2010/2009/decreto/d6861.htm>. Acesso em: 16 jan. 2018. 
. Lei no 9.394, de 20 de dezembro de 1996. Estabelece as diretrizes e bases da educação nacional. Diário Oficial da União, Brasília, 1996. Disponível em: <http://www.planalto.gov.br/ccivil_03/leis/L9394.htm>. Acesso em: 16 jan. 2018.

Lei n ${ }^{\circ} 11.645$, de 10 de março de 2008. Altera a Lei no 9.394, de 20 de dezembro de 1996, modificada pela Lei no 10.639, de 9 de janeiro de 2003, que estabelece as diretrizes e bases da educação nacional, para incluir no currículo oficial da rede de ensino a obrigatoriedade da temática "História e Cultura Afro-Brasileira e Indígena”. Diário Oficial da União, Brasília, 2008. Disponível em: <http://www.planalto.gov.br/ccivil_03/_ato2007-2010/2008/lei/111645.htm>. Acesso em: 16 jan. 2018.

- Ministério da Educação. Referencial Curricular Nacional para Escolas Indígenas (RCNEI). Brasília: MEC/SEF, 1998.

Disponível em: <http:/ /www.dominiopublico.gov.br/download/texto/me002078.pdf>. Acesso em: 18 jan. 2018.

- Ministério da Educação. Parâmetros Curriculares Nacionais (PCNs). Pluralidade Cultural. Brasília: MEC/SEF, 1997.

COHN, Clarice. A cultura nas escolas indígenas. In: CUNHA, Manuela Carneiro da; CESARINO, Pedro de Niemeyer (Orgs.). Politicas culturais e povos indígenas. São Paulo: Editora UNESP, 2016.

FREITAS, Itamar. A experiência indígena no ensino de História. Coleção Explorando o Ensino de História, v. 21. Ensino Fundamental. Brasília: Ministério da Educação, Secretaria de Educação Básica, 2010.

Disponível em:

<http://portal.mec.gov.br/index.php?option=com_docman\&view $=$ download\&alias=7839-2011-historia-capa-pdf\&category_slug=abril-2011-pdf\&Itemid=30192> . Acesso em: 19 jan. 2018.

GOMES, Mércio Pereira. Os indios e o Brasil: passado, presente e futuro. São Paulo: Contexto, 2012.

GRUPIONI, Luís Donisete Benzi. Os povos indígenas e a escola diferenciada: comentários sobre alguns instrumentos jurídicos internacionais. In: FISCHMANN, Roseli; VIDAL, Lux (Orgs.). Povos indígenas e tolerância: construindo práticas de respeito e solidariedade. São Paulo: Editora da Universidade de São Paulo, 2001a. 
GRUPIONI, Luís Donisete Benzi; SECCHI, Darci; GUARANI; Vilmar. Legislação Escolar Indígena. In: CONGRESSO BRASILEIRO DE QUALIDADE NA EDUCAÇÃO, 1, Brasília, out. 2001b. Anais... Brasília: MEC, SEF, 2001, p. 129-203. Disponível em: < http://portal.mec.gov.br/seb/arquivos/pdf/vol4a.pdf >. Acesso em: 16 jan. 2018.

MEDEIROS, Juliana Schneider. Povos indígenas e a Lei no 11.645: (in)visibilidades no ensino da História do Brasil. In: BERGAMASCHI, Maria Aparecida; ZEN, Maria Isabel Habckost Dalla; XAVIER, Maria Luisa Merino de Freitas (Org.). Povos indigenas e educação. 2. ed. Porto Alegre: Mediação, 2012.

MONTEIRO, John Manuel. Negros da terra: índios e bandeirantes nas origens de São Paulo. São Paulo: Companhia das Letras, 1994.

ORGANIZAÇÃO INTERNACIONAL DO TRABALHO. Convenção no 169 sobre povos indigenas e tribais e Resolução referente à ação da OIT/ Organizaçãa Internacional do Trabalho. Brasília: OIT, 2011.

Disponível em: < http://portal.iphan.gov.br/uploads/ckfinder/arquivos/Convencao_169_OIT.pdf>. Acesso em: 19 jan. 2018.

PALADINO, Mariana; ALMEIDA, Nina Paiva. Entre a diversidade e desigualdade: uma análise das políticas públicas para a educação escolar indígena no Brasil dos governos Lula. Rio de Janeiro: LACED/Museu Nacional/UFRJ, 2012.

SILVA. Aracy Lopes da. Educação para a tolerância e povos indígenas no Brasil. In: FISCHMANN, Roseli; GRUPIONI, Luís Donisete; VIDAL, Lux. (Org.). Povos indígenas e tolerância: construindo práticas de respeito e solidariedade. São Paulo: Editora da Universidade de São Paulo, 2001.

recebido em 2 mar. 2018 / aprovado em 9 abr. 2018

Para referenciar este texto:

POÇO, C. A.; DIAS, E. T. D. M. A educação escolar do indígena brasileiro. Cadernos de Pósgraduação, São Paulo, v. 17, n.1, p. 33-53, jan./jun. 2018. Disponível em: $<$ https://doi.org/10.5585/cpg.v17n1.8416>.

Cadernos de Pós-graduação, São Paulo, v. 17, n. 1, p. 33-53, jan./jun. 2018. 